\title{
LUCERNAS NORTE-AFRICANAS TARDIAS DE TERRA SIGILLATA: CURADORIA DE COLEÇÕES MUSEOLÓGICAS E PESQUISAS ARQUEOLÓGICAS
}

Maria Isabel D'Agostino Fleming1

\begin{abstract}
Resumo
As lucernas norte-africanas tardias de Terra Sigillata (African Red Slip Ware-ARS) formam uma categoria de objetos que, ao lado das vasilhas de mesa, adquiriram uma importância particular, não só pelo volume de sua produção, mas pelas suas implicações econômicas e comerciais, iconográficas e histórico-religiosas. Este artigo tem como objetivo apresentar o desenvolvimento de pesquisas fundamentais para 0 conhecimento sobre a produção e circulação da ARS e em particular as lucernas, tomando como exemplos diálogos profícuos entre os estudos curatoriais de coleções museológicas e pesquisas arqueológicas que apontam os limites dos modelos clássicos de estudo da cerâmica africana e realizam revisões acuradas de datações, origens e conteúdos das vasilhas, especialmente com métodos arqueométricos.
\end{abstract}

\section{Palavras-chave}

Lucernas norte-africanas (ARS); Coleções museológicas; Pesquisas arqueológicas; Produção; Circulação; Roma.

1 Professora Doutora, Universidade de São Paulo, São Paulo, Brasil. E-mail: mabelfleming@gmail.com 


\begin{abstract}
The Late African North African lamps of Terra Sigillata (African Red Slip Ware-ARS) are a category of objects which, alongside tableware, have acquired particular importance, not only for the volume of their production, but for their economic and commercial, iconographic and historical-religious implications. This article aims to present the development of fundamental research for the knowledge about the production and circulation of the ARS and in particular the lamps, taking as examples rich dialogues between the curatorial studies of museological collections and archaeological research that point the limits of the classical models of study of African ceramics and perform accurate reviews of dates, origins and contents of vessels, especially with archaeometric methods.
\end{abstract}

\title{
Keywords
}

North African lamps (ARS); Museum collections; Archaeological research; Production; Circulation; Rome. 
As lucernas norte-africanas tardias de Terra Sigillata (African Red Slip Ware-ARS) formam uma categoria de objetos que, ao lado das vasilhas de mesa, adquiriram uma importância particular, não só pelo volume de sua produção, mas pelas suas implicações econômicas e comerciais, iconográficas e histórico-religiosas. Mais recentemente um conjunto de estudos de coleções de museus e de pesquisas arqueológicas trouxe novas perspectivas de análise do papel que esses objetos desempenharam no contexto mediterrânico tendo como referência constante as vasilhas às quais, com raríssimas exceções, estavam atrelados, seja no campo da produção, isto é, no conjunto de oficinas das regiões norte-africanas central e setentrional, seja na circulação e distribuição para os centros consumidores.

Destaca-se no caso de acervos museológicos o trabalho hercúleo de Mariarosaria Barbera e Roberto Petriaggi, Museo Nazionale Romano - Le Lucerne Tard-Antiche di produzione Africana (1993) que estabeleceu uma tipologia extremamente detalhada das formas e dos motivos decorativos das lucernas norte-africanas de período tardio, numa amostragem de 305 peças que compõe o primeiro catálogo da coleção e representam um conjunto de mais de onze mil exemplares. Este trabalho curatorial de um material sem contextualização, proveniente de grandes escavações, mais especificamente terraplanagem, realizadas em Roma nas décadas pósunificação da Itália no século XIX, é um exemplo excepcional de aproveitamento científico de coleções de museus. Os resultados possibilitaram a revisão e reformulação da tipologia do Atlante delle forme ceramiche, I, Ceramica fine romana nel Bacino mediterraneo (medio e tardo impero) (Carandini et al., 1981). Nesse sentido, a tipologia estabelecida é referência obrigatória para grandes especialistas em ARS, dentre os quais, o principal é Michel Bonifay, do Centre Camille Julien (Aix-Marseille Université/CNRS) (Bonifay, 2003, 2004, 2005a, 2005b, 2007, 2011, 2013, 2014; Bonifay et al., 2013; Bonifay e Tchernia, 2012; Capelli e Bonifay, 2014).

\section{Produção e consumo - mercados interno e externo}

Entre as questões referentes à produção e consumo das lucernas norteafricanas tardias, há que ser considerado o problema de mercados diferenciados no âmbito interno, da região central e setentrional da Tunísia, e a esfera mediterrânica. Os produtos de alimentação africanos, como o trigo, o óleo de oliva, o vinho e as salmouras de peixe, salsamenta, garum, são as possíveis referências associadas à difusão das lucernas e da ARS e em se tratando da destinação interna ou para a exportação, eram 
diferentes as oficinas em que eram fabricadas. Um dos produtos de consumo interno, como o óleo de oliva, era conduzido em odres ou tonéis, recipientes mais leves para transporte terrestre, e podiam ser acompanhados por carregamentos cerâmicos até a costa. Para a exportação, era acondicionado em ânforas. Entretanto, no Mediterrâneo, a difusão da ARS em regra geral parece completamente desconectada do comércio das ânforas e, antes, ligada ao comércio de cereais, no caso o trigo (Clay, 1992: 353; Panella, 1993: 639 apud Bonifay 2005: 576, nota 72) pelo menos até a conquista vândala. A associação do trigo ao comércio e difusão das lucernas e ARS pode ser traçada numa perspectiva de longa duração referente aos sítios consumidores no Ocidente e Oriente. Segundo Bonifay e Tchernia (2012: 328):

Precedido, desde a primeira metade do séc. I, pelas chegadas não negligenciáveis de cerâmicas culinárias africanas, não somente a Roma, mas igualmente à Espanha (Aguarod Otal 1991: 239), o início das importações africanas no Ocidente é muito rápido. Estas importações atingem seu máximo desde o início do século II (Fentress et al. 2004: fig. 11.3), o que está em harmonia com o que sabemos sobre a evolução das importações de trigo africano em Roma. Em contraste, o começo é mais lento no Oriente, onde devemos esperar até meados do século III para obter figuras equivalentes (Bes 2007: Fig. 2). Não se sabe explicar a queda das importações assinalada em todo o Mediterrâneo na segunda metade do século terceiro e no início do século IV (Fentress et al. 2004: 149; Bes 2007: 191): as ferramentas tipo-cronológicas utilizadas podem estar envolvidas (Fentress et al. 2004: 148), mas provavelmente elas apenas exageram uma possível crise da produção e também algumas mudanças nas maneiras de comercialização. Mais significativa, sem dúvida, mas também tão difícil de explicar, é a segunda queda das importações no século $\mathrm{V}$. Todas as contas parecem indicar que ela começa bem antes da conquista vândala (Fentress et al., 2004: 149, Bes 2007: 193). No entanto, embora outras causas possam ser invocadas, como declínio da população (e, portanto, de consumo) em Roma e outras cidades por volta de 400 d.C. (Zanini, 1996: 682 e fig. 9), é talvez excessivo querer negar todo o efeito do que foi para o Império uma das maiores catástrofes do século: a perda política e depois econômica dos territórios africanos. Aí ainda a aferição cronológica das tipologias pode estar envolvida.

Ainda na questão da difusão / importação de lucernas e ARS associada predominantemente ao suprimento de trigo para Roma e províncias, os cruzamentos de dados e tipologias apresentados pelas pesquisas de coleções (Carandini et al., 1981; Barbera e Petriaggi, 1993) e de escavações sistemáticas de sítios arqueológicos forneceram perspectivas interessantes quanto aos trajetos percorridos pelas embarcações. Tais estudos têm como referência essencial a questão prática, estratégica e econômica do fluxo dos navios nos dois sentidos do percurso que executavam, de modo a garantir que estivessem sempre carregados. Tendo em vista os mercados e a destinação da cerâmica africana, são propostas algumas 
hipóteses sobre os possíveis trajetos executados (Bonifay e Tchernia, 2012: 326 e Fig. 16.5). As pesquisas sugerem linhas diretas especialmente para Roma tendo em vista a importância do tráfico. Entretanto, esses trajetos em linha direta não eram destinados ao abastecimento da cidade a partir de Cartago, segundo referências a um navio que ligava diretamente Óstia a partir de Hipona (Hippo Regius) (Digeste 14.2.6). Compunham esses trajetos também as linhas indiretas, tendo em conta o papel desempenhado pelos carregamentos de retorna à África. Fentress et al., 2004 (apud Bonifay e Tchernia, 2012: 326) sugeriram que Roma poderia ter desempenhado um papel de um porto-entreposto entre a África e a Sicília, uma parte do abastecimento da ilha em ARS seria assegurada pelos navios de comércio que retornavam de Roma para a África. Da mesma forma foi sugerido que Alexandria tenha sido alimentada de ARS pelos carregamentos de retorno dos navios da anona (Bes, 2007: 190, apud Bonifay e Tchernia 2012: 326). Uma extensão desse modelo pode ser proposta considerando as condições naturais relativas ao regime dos ventos dominantes que tornam impossível o trajeto Alexandria-Roma ao longo da costa da Cirenaica a partir de junho. Nesse caso seria conveniente navegar primeiramente na direção de Chipre a nordeste e posteriormente chegar à Lícia e enfim dar uma guinada para Rodes e o sul de Creta (Arnaud, 2005: 13, apud Bonifay e Tchernia, 2012: 326). Assim, uma lucerna ou vaso de Terra sigillata africana presentes em Creta poderiam ter viajado primeiramente da África a Roma, depois de Roma a Alexandria na direção do Mar Egeu em função das oportunidades das partidas dos navios e do regime sazonal dos ventos. Finalmente, a cabotagem complementa a forma de redistribuição das mercadorias a partir dos portos principais, tem um papel bem conhecido e pode às vezes assegurar a difusão primária dos produtos. Para a ARS parece ser bem o caso do sudoeste da Sicília em virtude da proximidade das costas africanas (Fentress et al., 2004, apud Bonifay e Tchernia 2012: 326). A Numídia e a Mauretânia Cesariense, sul da Sardenha e a Cirenaica poderiam igualmente, em razão da proximidade, seguir este regime de difusão aleatória das cerâmicas africanas (Bes, 2007, apud Bonifay e Tchernia 2012: 326). (Figura 1) 
Tipologia e centros de produção das lucernas de cerâmica sigillata africana tardia

Os centros de produção principais encontravam-se na Tunísia Central (Bizacena) e Setentrional (Zeugitana). A associação estreita entre a ARS e as lucernas é estabelecida por investigações sobre o nível de dependência das últimas em relação às primeiras tendo como referência os motivos decorativos. Um estudo sistemático, por um lado, observou as conexões entre as formas e os tipos de lucernas nas quais os mesmos motivos decorativos aparecem e, por outro lado, sua relação com as ornamentações, em parte análogas, que se encontram nos vasos de sigillata africana. Este salto de qualidade da pesquisa realizada por Barbera e Petriaggi (1993) possibilitou uma quantidade de informações inéditas em dois campos decisivos: a cronologia das decorações - que, por sua vez se reflete sobre a datação dos tipos ou dos exemplares isolados - e a associação entre a produção de lucernas e as produções vasculares em ARS.

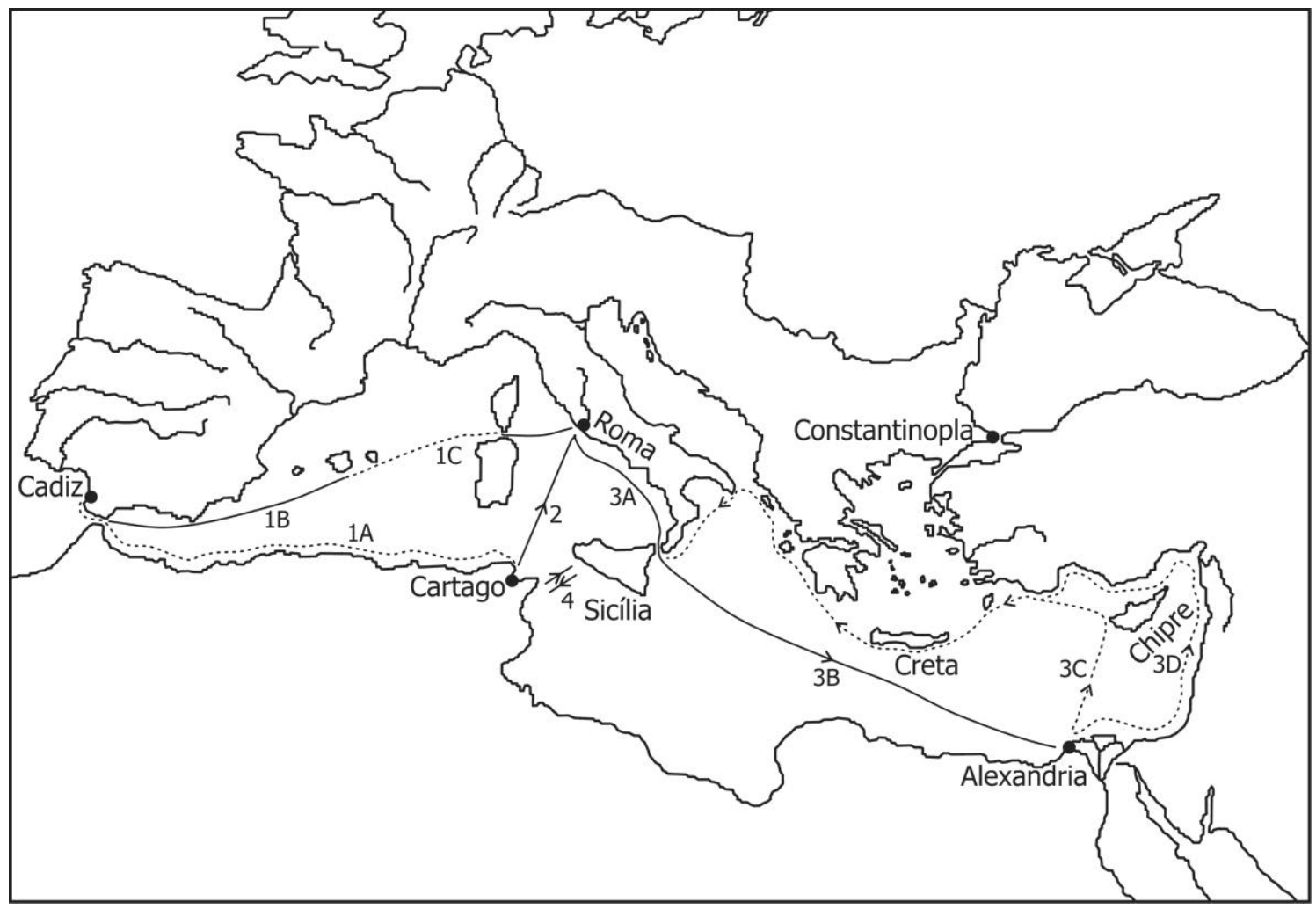

Fig. 1. Modelos de difusão das ânforas e das sigillatas africanas: 1. carregamentos heterogêneos africanos/hispânicos; 2. linha direta Cartago-Roma; 3. carregamentos de retorno para Alexandria e prolongamentos; 4 cabotagem do estreito da Sicília. Fonte: modificado de Bonifay e Tchernia (2012: Fig. 16.5).

Em termos de interação desejável entre pesquisas de coleções com material descontextualizado e escavações arqueológicas com material de 
contexto conhecido pôde-se constatar que o início da fabricação e a duração do uso das principais produções de lucernas em ARS proposto por Barbera e Petriaggi (1993) foram confirmados por pesquisas estratigráficas de algumas grandes escavações das décadas de 1970-80 de Cartago, um dos centros principais de produção das lucernas de ARS. Entretanto, o quase exaurimento da importação de lucernas por Roma, as denominadas "africanas clássicas" (tipo Atlante, Forma X) depois da metade do séc. VI d.C., é uma informação que emerge do estudo dos motivos decorativos da coleção do Museo Nazionale Romano, o qual serviu de apoio a outras importantes publicações sobre a distribuição das lucernas tardias africanas nos centros de produção africanos da Tunísia Central e Setentrional. O estudo de Bonifay (2005b) baseou-se em escavações de uma necrópole urbana utilizada do séc. II ao IV d.C. em Pupput (Hammamet); três basílicas cristãs do séc. V ao VII d.C., em Sidi Jdidi (Aradi), e uma fábrica de salga de peixes, com estratigrafia contínua do séc. I ao VII d.C., em Nabeul (Neapolis), sendo que os sítios de Pupput e Nabeul estão situados na costa da Tunísia Setentrional e Sidi Jdidi encontra-se a poucos quilômetros para o interior na mesma região. Bonifay (2005b) apresenta a tipologia das lucernas africanas do séc. II ao VII d.C. e tem uma parte dedicada especificamente aos exemplares tardios de sigillata africana do tipo Atlante $X$, cuja proposta é a distribuição em dois grandes grupos em função do estilo das decorações: um afiliado à sigillata $\mathrm{C}$, do centro da Tunísia e o outro afiliado à sigillata D, do norte da Tunísia. (Figuras 2 e 3). Por outro lado, a análise da coleção do Museo Nazionale Romano levou adiante as hipóteses sobre as áreas de produção das lucernas em ARS, isto é, dos dois principais filões em que a produção se divide. Esses filões compreendem a quase totalidade dos exemplares exportados, que são a série 4 (tipo Atlante, Forma VIII - também incluído no conjunto de tipos analisados por Bonfay 2005b) e 6 (tipo Atlante, Forma X) .

É de fato no campo da detecção dos centros de fabricação que o confronto, acima referido, entre motivos decorativos das lucernas e os das vasilhas em ARS fez surgirem os resultados mais inovadores. As observações de Barbera e Petriaggi (1993) permitiram estabelecer que as decorações da série 4, na sua maioria absoluta, não possuem paralelos com as decorações vasculares e que, entretanto, num limitado número de casos é possível remontar a uma possível inspiração comum. Essas exceções possibilitaram situar três exemplares ao repertório decorativo das diversas produções vasculares de sigillata africana $C$, localizadas na Tunísia Central e cinco exemplares a vasos de sigillata africana D, cuja área de origem é a Tunísia Setentrional. Quanto a sua difusão, os exemplares da série 4 estão presentes em toda a área costeira do 
Mediterrâneo ocidental, no Egito e na antiga Iugoslávia. Esse pequeno conjunto de lucernas, cujas hipóteses de seus centros de fabricação eram vagas, deu início ao preenchimento de uma lacuna científica. A dificuldade até agora encontrada pelos estudiosos em colocarem geograficamente essa produção se explica, contudo, pelo menos em parte, justamente com a estranheza de grande parte do patrimônio ornamental das lucernas da série 4 em ralação ao vascular.

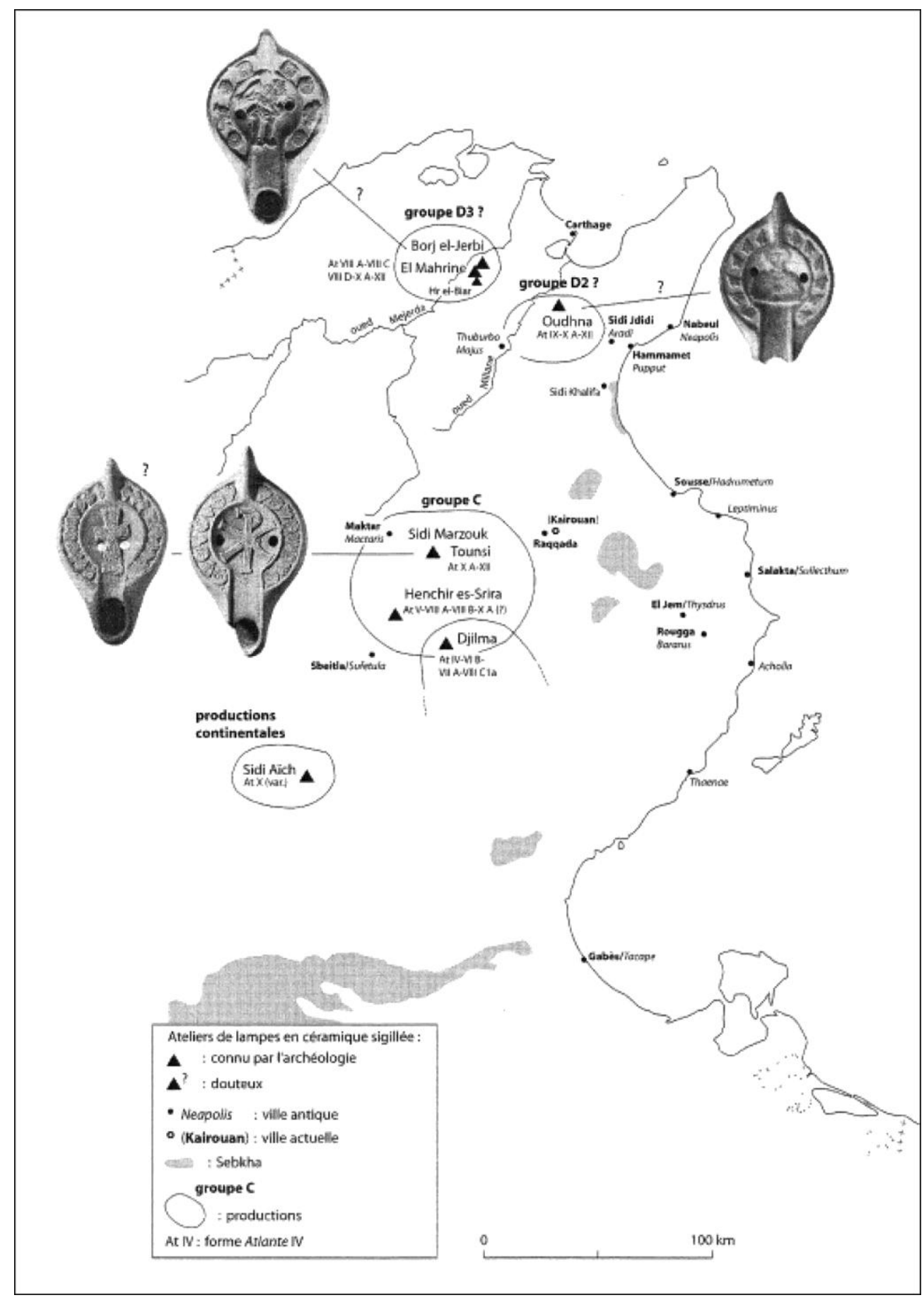

Fig. 2. Lucernas tardias em sigillata africana (tipo Atlante $X$ ): proposição de localização dos diferentes grupos de produção. Fonte: Bonifay, 2005b: Fig. 5. 


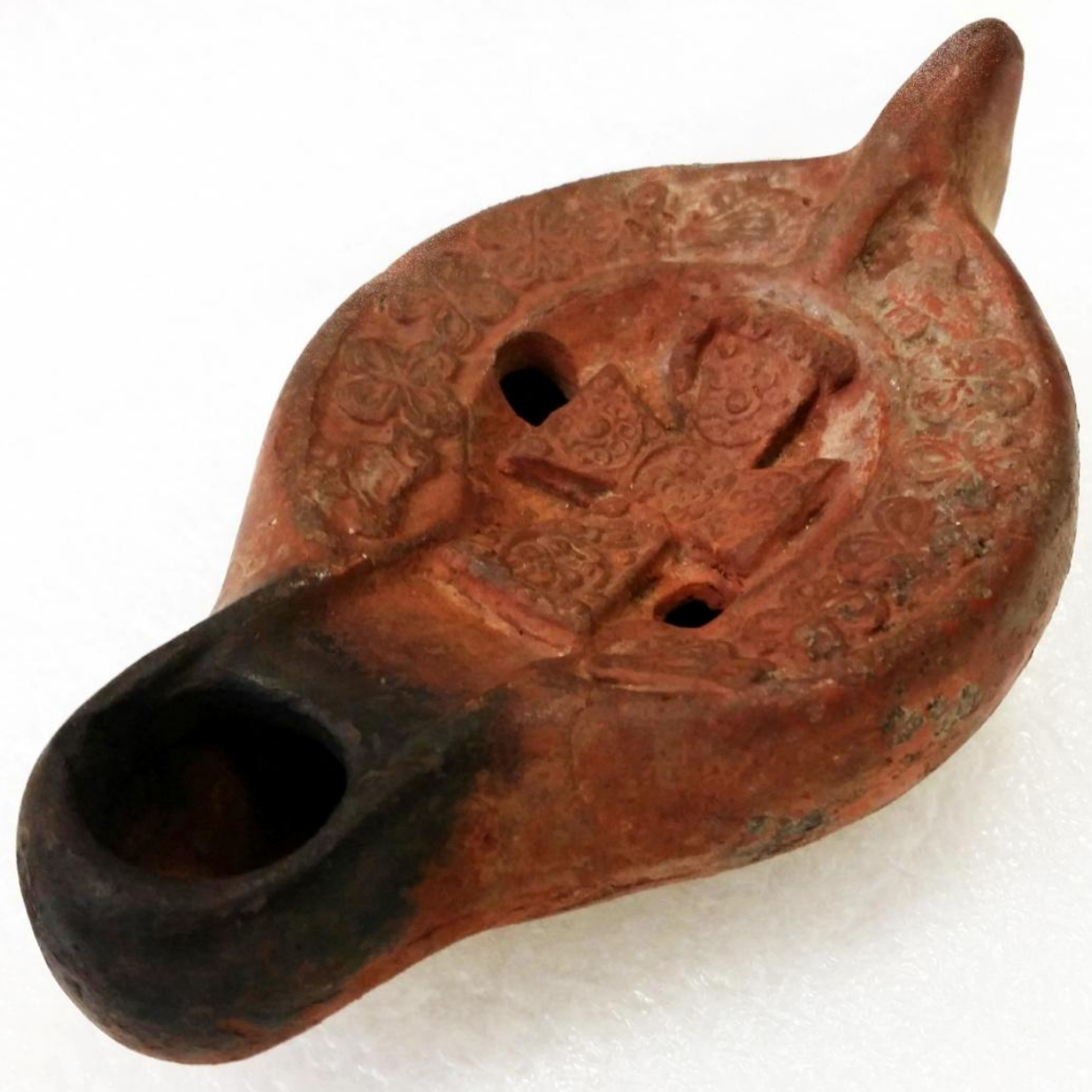

Fig. 3. Lucerna tardia de sigillata africana (tipo Atlante X), séc. V-VII d.C. Acervo Museu de Arqueologia e Etnologia-USP.

Quanto à análise das lucernas da série 6 (tipo Atlante, Forma X) do Museo Nazionale Romano, essas, de fato, apresentam confrontos muito mais numerosos com as decorações documentadas nos vasos em ARS, mesmo que seja identificada uma área decorativa autônoma em relação à dos vasos. Tais confrontos frequentemente não se limitam a uma semelhança genérica, mas são diretos e precisos. Os paralelos com a produção da Tunísia Central (Bizacena) e Setentrional (Zeugitana) possibilitaram confirmar e precisar algumas intuições de Hayes (1972: 312) ampliando notavelmente o alcance (Barbera e Petriaggi, 1993: 8). Surgiu uma rica variedade de relações com as diversas produções da sigillata africana C da Tunísia Central, com diferentes técnicas de decoração e da sigillata africana D da Tunísia Setentrional, decoradas com molde. A circulação das chamadas "africanas clássicas" atingiu a inteira bacia mediterrânica, mesmo que seja preciso destacar que a enorme e capilar difusão nas regiões ocidentais, especialmente ao longo das costas italianas, não encontra paralelo análogo na área oriental. 


\section{Lucernas e vasos de terra sigillata - produção em oficinas independentes}

Os autores propõem uma hipótese interessante do ponto de vista dos centros de produção (Barbera e Petriaggi, 1993: 424) e da separação da produção de vasilhas e de lucernas em oficinas independentes: as duas grandes séries não parecem poder ser atribuídas a duas áreas distintas e separadas. Ao contrário, ambas teriam tido relações seja com a produção de cerâmica vascular localizada na Tunísia Central, seja com a correspondente à Tunísia Setentrional. Para as lucernas da série 4 as conexões com o vasilhame produzido nas duas áreas, entretanto, se colocariam apenas no plano de uma retomada genérica de iconografia e estilos decorativos. De fato, os motivos decorativos são muito menos cuidados e executados de modo mais apressado e aproximativo. Parece, em suma, que essas lucernas possam ser atribuídas a oficinas especializadas nesta classe de cerâmica, mas marginais em relação aos grandes circuitos produtivos e comerciais. As lucernas clássicas, no entanto, em um número pequeno de casos podem ser atribuídas às mesmas oficinas de vasos em ARS, mas parece tratar-se de episódios e não a regra. A afirmação da separação de oficinas de vasos e de lucernas se apoia no fato de que um achado, até agora único, com uma breve nota preliminar sobre a oficina de el Mahrine (Mackensen 1985: 29, apud Barbera e Petriaggi, 1993: 425) no interior de Cartago, dá detalhes dos estilos das vasilhas e suas formas específicas e quanto às lucernas se limita a citar a existência também de "tipos Hayes I e II". "Do artigo não se consegue entender a quais - entre os numerosos tipos que compõem a série 4 - o autor se refira: de fato, a tal série correspondente ao tipo Hayes, pertencem também tipos com discos lisos ou decorados com simples motivos geométricos. Além disso, Mackensen permanece vago também no que se refere ao percentual de tipos 4 em relação às africanas clássicas e ao vasilhame" (Barbera e Petriaggi, 1993: nota 8). No que se refere à relação entre as séries 4 e 6, os autores propõem em linhas gerais que as oficinas que produziam lucernas da série 4 com decoração figurada no disco e lucernas da série 6 não produzissem vasilhas em ARS.

A evidente diferença qualitativa entre as duas séries pode ser explicada dentro da mesma oficina, pensando em produções distintas porque de custos diversos, e não devido ao recurso a artesãos mais refinados para a série 6. Os autores propõem que no longo período de coexistência entre a série 4 e as africanas clássicas, do primeiro quartel do séc. $V$ à metade do séc. VI aproximadamente, provavelmente a produção de lucernas fosse realizada em três diversos e complementares tipos de oficinas (Barbera e Petriaggi, 1993: 425): 
A - oficinas secundárias, de papel marginal em relação aos centros econômicos locais;

B - oficinas de importância intermediária, que imitam os modelos iconográficos da produção vascular em ARS;

C- oficinas principais, que produzem prevalentemente vasilhame e, secundariamente, lucernas em ARS.

Ao primeiro grupo de oficinas podem ser atribuídas as lucernas da série 4, em particular as mais distantes de confrontos vasculares, que são geralmente de qualidade bastante modesta. Ao segundo grupo poderiam ser atribuídos os melhores entre os exemplares da série 4 e as menos cuidadas entre as africanas clássicas. Quanto à relação com o vasilhame em ARS, enquanto parece quase certo excluí-lo da produção das oficinas do primeiro grupo, permanecem algumas dúvidas em mérito aos outros dois grupos. De fato, a análise dos motivos decorativos permite levantar a hipótese de que as oficinas de tipo $B$ girasse em torno a lucernas de série 4 e 6, mas não de vasilhame em ARS e que as oficinas de tipo C produzissem vasos e lucernas apenas da série 6, e não da série 4 .

A hipótese levantada por Barbera e Petriaggi aguarda confirmações para que as discussões possam prosseguir.

\section{Considerações finais}

As vasilhas de terra sigillata africana tardia, incluídas as lucernas nesta categoria, tiveram Roma como mercado principal, confirmado por dois tipos de fontes. Por um lado, testemunhos arqueológicos de escavações, ou melhor definindo, achados, que remontam ao séculos XVIII e XIX, sobretudo, frutos de uma concepção da relação com o antigo marcado essencialmente pelo colecionismo, coleta esporádica de materiais que afloraram à superfície, por uma prática de escavação completamente ignorante da existência da estratigrafia. Por outro lado, estudos mais recentes, dedicados à investigação de redes do comércio mediterrânico (Arnaud, 2005, Bonifay e Tchernia, 2012, Clay, 1992). Entretanto, se nos tempos atuais são objeto de escavações sistemáticas, vasilhas e lucernas foram em sua maior parte trazidas à luz por trabalhos de terraplanagem de obras urbanísticas efetuadas no período pós-unificação da Itália, condições bastante adversas que impediram sua contextualização. Em termos quantitativos pode-se fazer um paralelo ousado com o Monte Testaccio, que mantém estratos ordenados de fragmentos de ânforas quebradas predominantemente do tipo Dressel 20, provenientes da 
Bética, com tituli picti, e em menor número dois tipos de ânforas da Tripolitana, Líbia, e Bizacena, Tunísia. Em termos qualitativos, entretanto, no lugar das informações que podem ser extraídas das ânforas, as vasilhas e lucernas em ARS eram objetos de origem desconhecida ou traziam dados de inventário de proveniência extremamente genéricos das várias regiões de Roma. Em um volume excepcional foram literalmente encaminhados para os museus de Roma. O cenário que enfrentam os pesquisadores e o corpo técnico-científico dos museus é o de viver uma fase da história da arqueologia marcada sempre mais pela sensibilidade estratigráfica e, ao mesmo tempo, dever fazer as contas com um dos legados da arqueologia das décadas passadas. A extraordinária importância da coleção do Museo Nazionale de Roma, neste texto analisada, entretanto, não se deve apenas à sua amplitude. O papel de capital do mundo antigo desempenhado por Roma a partir da República tardia, como ponto de chegada dos comércios, especialmente marítimo, provenientes de qualquer ponto do Império, se reflete na composição da coleção, que acaba por constituir uma espécie de amostragem representativa, quase sem exceção, do inteiro panorama das tipologias e das produções que se sucederam na bacia mediterrânica da metade do período republicano romano até o final da antiguidade (Pavolini, 1993: 3). As pesquisas de coleções museológicas tomaram força especialmente desde as décadas dos anos 1970-80 e resultaram em catálogos sistemáticos de grande importância, como o Atlante delle forme ceramiche, I, Ceramica fine romana nel Bacino mediterraneo (medio e tardo impero) (Carandini et al., 1981). O trabalho empreendido com esses acervos envolve estudar e compreender as razões históricas e culturais que levaram a esse modo de formação, hoje não mais aceitável, da grande parte das coletas arqueológicas e, sobretudo, atribuir ao dever científico resolver os problemas na maneira mais rigorosa, com os padrões atuais, criando critérios adequados de estudo e de publicação

Nos tempos recentes, os estudos sobre a produção, datação e distribuição da cerâmica e lucernas em ARS passam por inúmeras discussões e revisões dos principais conjuntos cerâmicos mediterrânicos, com vistas a resolver problemas de tipologia e cronologia além da atribuição da localização dos centros de produção. É amplo o cenário das pesquisas que chamam a atenção para os limites dos modelos clássicos de estudo da cerâmica africana e realizam revisões acuradas de datação, origem e conteúdo das vasilhas, especialmente com métodos arqueométricos (Capelli, Bonifay, 2014; Cau et al., 2012). Por outro lado, o mercado consumidor mais importante do Império tem guardados em seus museus os principais testemunhos desse movimento que envolveu praticamente todas as províncias e num período de pelo menos nove séculos. $\mathrm{O}$ 
trabalho realizado com a coleção de lucernas em ARS do Museo Nazionale Romano é a confirmação de que este fato não poderia ser ignorado e possibilitou a integração de seu acervo àqueles de contextos bem determinados de centros produtores norte-africanos, ao mesmo tempo em que serviu de referência tipológica e cronológica para as pesquisas mais avançadas da atualidade sobre cerâmica sigillata norteafricana tardia. Trata-se, portanto, de um exemplo do diálogo entre formas de pesquisa complementares essencial ao desenvolvimento do conhecimento científico em que vencem as duas partes.

\section{Referências bibliográficas}

AGUAROD OTAL, C. Cerámica romana importada de cocina em la Tarraconense. Saragosse: Institución Fernando el Católico, 1991. Apud (Bonifay e Tchernia, 2012: 328.

ARNAUD, P. Les routes de la navigation antique. Itinéraires en Méditerranée. Paris: Errance, 2005. Apud Bonifay e Tchernia 2012: 326.

BARBERA, Mariarosaria; PETRIAGGI, Roberto Museo Nazionale Romano Le Lucerne Tard-Antiche di produzione Africana. Roma: Istituto Poligrafico e Zecca dello Stato, 1993.

BES, P. A Geographical and Chronological Study of the Distribution and Consumption of Tablewares in the Roman East. Leuven: Katolieke Universiteit Leuven, thèse de doctorat, 2007. Apud Bonifay e Tchernia, 2012: 328 .

BONIFAY, Michel. La céramique africaine, un indice du développement économique? AnTar, 2003, 11: 113-128.

BONIFAY, Michel. Études sur la céramiqueromaine tardive d'Afrique, BAE Int. Ser. 1301. Oxford: Archaeopress, 2004.

BONIFAY, Michel. Observations sur la diffusion des céramiques africaines en Méditerranée orientale durant l'Antiquité tardive. In : BARATTE (F.) et al. (ed.) Mélanges Jean-Pierre Sodini (Travaux et Mémoires, 15). Paris: Collège de France, 2005a: 565-581.

BONIFAY, Michel. In: CHRZANOVSKI, Laurent (Dir.) Lychnological Acts 1. Actes du 1erCongrès international d'études sur le luminaire antique. Nyon Genève, 29. IX - 4.X.2003. montagnac: éditions monique mergoil, 2005b: 31-38 e pl. 12-16. 
BONIFAY, Michel. Ceramic Production in Africa During Late Antiquity: Continuity and Change. In: LAVAN, Luke; ZANINI, Enrico e SARANTIS, Alexander (eds.) Technology in Transition A.D. 300-650. Leiden, Boston: Brill, 2007: 143-158.

BONIFAY, Michel. Production et diffusion des céramiques africaines durant l'antiquité tardive. In: ATTOUI, Redha (ed.) When did Antiquity end? Archaeological case studies in three continents. The Proceedings of an International Seminar held at the University of Trento on April 29-30, 2005 on Late Antique Societies, Religion, Pottery and Trade in Germania, Northern Africa, Greece and Asia Minor. Oxford: BAR International Series, 2011: 15-30.

BONIFAY, Michel. Africa: Patterns of Consumption in Coastal Regions Versus Inland Regions. The Ceramic Evidence (300-700 A.D.). In: LAVAN, L. (ed.) Local Economies? Production and Exchange of Inland Regions in Late Antiquity. (Late Antique Archaeology 10) Leiden: Koninklijke Brill NV, 2013: 529-566.

BONIFAY, Michel. Céramique africaine et imitations: où, quand, pourquoi? In: MORAIS, R.; FERNANDEZ, A.; SOUSA, M.J. (eds.) As Produções Cerâmicas de Imitação na Hispania. Monografias Ex Officina Hispana II, Tomo I, 2014: 75-91.

BONIFAY, Michel; CAPELLI, Claudio, avec la collaboration de FRANCO, Carmela; LEITCH, Victoria; RICCARDI, Laurent e BERNI MILLET, Piero. Les Thermes du Levant à Leptis Magna: quatre contexts céramiques des IIIe et IVe siècles. In: GRIESHEIMER, Marc; GASCOU, Jacques (eds.) Antiquités Africaines. Paris: CNRS Éditions, 2013: 67-150.

BONIFAY, Michel; TCHERNIA, André. Les réseaux de la céramique africaine (IER-VE siècles). In: KEAY, Simon (ed.) Rome. Portus and the Mediterranean. Archaeological Monographs of The British School at Rome. Rome: The British School at Rome, 2012: 315-333.

CAPELLI, Claudio; BONIFAY, Michel. Archéometrie et Archéologie des Céramiques Africaines: une Approche Pluridisciplinaire, 2 Nouvelles Données sur la Céramique Culinaire et les Amphores. In: POULOPAPADIMITRIOU, Natalia; NODAROU, Eleni; KILIKOGLOU, Vassilis (eds.) LRCW 4. Late Roman Coarse Wares, Cooking Wares and Amphorae in the Mediterranean. Archaeology and archaeometry. The Mediterranean: a market without frontiers. Volume 1. BAR International Series 2616 (I). Oxford: Information Press, 2014: 235-253.

CARANDINI; Andrea; ANSELMO, L.; PAVOLINI, Carlo; SAGUİ, L.; TORTORELLA, S.; TORTORICI, E. Atlante delle forme ceramiche, I, 
Ceramica fine romana nel Bacino mediterraneo (medio $e$ tardo impero),Enciclopedia dell'arte antica. Roma: Treccani, 1981.

CLAY. T. Carthage et son commerce dans l'Antiquité tardive. In: AFRIQUE DU NORD ANTIQUE ET MÉDIEVALE, SPECTACLES, VIE PORTUAIRE, RELIGIONS, Actes $d u$ Ve Colloque international sur l'Histoire et l'Archéologie de l'Afrique du Nord (Avignon, 9-13 avril 1990). Paris, 1992: 349-359. Apud Bonifay 2005a: 576, nota 72.

FENTRESS, L.; FONTANA, S., HITCHNER, B.; PERKINS, P. Accounting for ARS: fineware and sites in Sicily and Africa. In: ALCOCK, Susan;. Cherry. J. (eds.) Side by Side Survey. Comparative Regional Studies in the Mediterranean World: 147-62. Oxford: Oxbow, 2004. Apud Bonifay e Tchernia, 2012: 238

HAYES, John W. Late Roman Pottery. London: British School at Rome, 1972. Apud Barbera e Petriaggi, 1993: 8.

MACKENSEN. Michael. Die spätantiken Sigillata - und Lampentöpfereien von el Mahrine (Nordtunisien): Studien zur nordafrikanischen Feinkeramik des 4. Bis 7. Jahrhunderts / mit ein Beitrag von Sebastian Stortz. München: C.H. Beck'sche Verlagsbuchhandlung, 1985. Apud Barbera e Petriaggi, 1993: 425.

PANELLA, Clementina. Merci e scambi nel Mediterraneo tardoantico. In: Storia di Roma III, 2. Turim: Einaudi, 1993: 614-697. Apud Bonifay 2005a: 576 , nota 72 .

PAVOLINI, Carlo. Introduzione. In: BARBERA, Mariarosaria; PETRIAGGI, Roberto Museo Nazionale Romano - Le Lucerne Tard-Antiche di produzione Africana. Roma: Istituto Poligrafico e Zecca dello Stato, 1993: 19.

ZANINI, E. Ricontando la terra sigillata africana. Archeologia Medievale.Siena: Università degli Studi di Siena - Dipartimento di Archeologia e Storia delle Arti, 23, 1996, 677-688. Apud Bonifay e Tchernia, 2012: 328. 